\title{
TRANSARTE OU INTERARTE? ${ }^{1}$
}

Sandra Regina Ramalho e Oliveira ${ }^{2}$

Maria de Lourdes de Azevedo ${ }^{3}$

Fernanda Maziero Junqueira ${ }^{4}$ Débora da Rocha Gaspar ${ }^{5}$

\section{RESUMO}

Este é mais um relato da terceira etapa do Projeto TRANSARTE, proposta de ensino de arte baseada na Semiótica. A primeira experiência se deu em uma escola pública federal e a segunda, em escolas das redes públicas estadual e municipal; a terceira, deu-se numa escola particular. Diversas dificuldades com os professores reduziram a proposta de transdisciplinaridade para interdisciplinaridade. Os resultados obtidos mostram dados relevantes em relação à percepção de intersemioses, à ampliação de repertório de conceitos e à leitura de imagens, considerados os desempenhos nos pré e pós-testes.

PALAVRAS-CHAVE: Ensino de Arte. Transdisciplinaridade. Intersemioses.

\section{Introdução}

Este é o terceiro artigo que escrevo sobre o mesmo assunto: a terceira etapa do Projeto TRANSARTE. Isto porque eu não apenas assinei os artigos escritos por minhas orientandas; nem apenas corrigi o que escreverem. Trabalhamos conjuntamente todo o tempo e muitos trechos dos artigos delas foram escritos por mim, quando as limitações inerentes a um iniciante se manifestavam, ocasião nas quais aproveitava para mostrar a elas o que deveria ser escrito e o seu porquê. Também muitas coisas foram a elas ditadas por mim, principalmente quando encontravam dificuldades para resumir a complexidade das questões observadas, que tinham que ser colocadas em palavras. Assim sendo, em se tratando de autoria do artigo final, minhas orientandas foram adequadamente orientadas. E ainda quanto à autoria, se meu nome lá consta é porque fui, efetivamente, co-autora. Assim, é muito penoso ficar aqui tentando dar uma nova redação para um artigo já escrito

\footnotetext{
Projeto "TRANSARTE: trandisciplinaridade e intersemioses no ensino de arte", Centro de Artes/CEART.

Orientadora, Departamento de Artes Plásticas.

Bolsista PIBIC/CNPq.

Bolsista PROBIC.

Voluntária, Professora da Unisul.
} 
e re-escrito, por uma exigência burocrática do império da desconfiança no qual se transformou a Universidade.

Eis aqui então mais um relato da terceira etapa do Projeto TRANSARTE. Iniciado em 2004, com o título de Intersemioses e Transdisciplinaridade no Ensino da Arte, seus resultados mostraram que seria necessário aplicá-la em outras realidades, distintas daquela, a de uma escola pública federal. A partir da segunda etapa, chamou-se Projeto TRANSARTE, desenvolvido em três etapas (três experiências de campo), assim denominadas: TRANSARTE I (denominação retroativa), TRANSARTE II e TRANSARTE III.

O Projeto TRANSARTE consistiu, em síntese, em aplicar, em escolas das redes públicas e particular de ensino, uma proposta de ensino transdisciplinar, com base em princípios da semiótica discursiva, para a construção coletiva de aulas das três linguagens da arte: artes plásticas, música e artes cênicas, a partir de uma abordagem proposta pelos pesquisadores, a ser ajustada, amadurecida, discutida e adaptada em decorrência da convivência do grupo de pesquisa com os professores, nas escolas.

O TRANSARTE I ocorreu em uma escola pública federal, com alunos de uma primeira série do Ensino Médio, durante o primeiro semestre de 2005; já o TRANSARTE II ocorreu em duas quintas séries do Ensino Fundamental de uma escola pública municipal de Florianópolis, no segundo semestre de 2006. Os resultados das duas intervenções mostraram que mesmo havendo dificuldade para reunir os professores, o resultado com os alunos mostravam que eles conseguiam estabelecer as intersemioses. Os resultados obtidos junto às escolas das redes públicas mostravam a necessidade de mais uma testagem, em uma escola particular, porque, imaginava-se, uma escola privada teria como gerar espaços para estudo, planejamento e avaliação, ou seja para reunir professores.

Em todas as suas etapas, o projeto TRANSARTE desenvolveu-se com fundamentos da semiótica para efeitos de concepção de textos estéticos e suas respectivas linguagens; no que se refere à metodologia de ensino, teve como paradigma os três enfoques que compõem a Abordagem Triangular de Ana Mae Barbosa (1998), depois adotados nos Parâmetros Curriculares Nacionais (PCN's), na área de Arte: 
contextualização, leitura da imagem e fazer artístico, mas tendo como ponto mais enfático a leitura de imagens.

A semiótica visual, de matriz greimasiana, está presente apenas para a compreensão da Arte como linguagem, análoga à linguagem verbal; os princípios e paradigmas utilizados para a compreensão de uma determinada linguagem (teatro, ou música, ou artes visuais, ou poesia) são adotados para relações com fenômenos análogos em outras linguagens (visual, sonora, cênica, audiovisual).

TRANSARTE questiona o seguinte: como a Escola vai dar conta da construção de um sujeito cidadão "imagemizado" (ou seja, alfabetizado em outras linguagens, além da verbal), quando só possui um professor formado em uma única linguagem artística? Ou, no caso específico do TRANSARTE III, no qual a Escola dispõe de professores das três linguagens adotadas oficialmente em Santa Catarina: como os professores de Arte somarão seus conhecimentos para multiplicar os de seus alunos? O objetivo do TRANSARTE III era testar, numa escola particular, uma abordagem transdisciplinar baseada na semiótica discursiva, correlacionando artes plásticas, música e artes cênicas, entendendo que os conteúdos e práticas das três linguagens pudessem "atravessar-se" mutuamente, estabelecendo e percebendo analogias e distinções entre si, estendendo percepções para as vivências cotidianas.

Quanto ao conceito de transdisciplinaridade estudamos Nicolescu (2002), Zabala (2004) e Melo, Barros e Sommerman (2002) e quanto à interdisciplinaridade Ana Mae Barbosa (1984). No tocante aos princípios semióticos consultamos: A. G. Greimas (fundamentos), D. Pignatari (poesia e arquitetura), A. C. Oliveira (linguagem visual) e J. Plaza (intersemioses); em artes visuais, F. Ostrower, R. Arnheim, W. Kandinsky; música, M. Schaefer e teatro, P. Pavis.

Constatamos, no TRANSARTE III, que os alunos conseguem estabelecer relações entre as linguagens e ampliar seu repertório de conceitos estéticos, embora as aulas tenham sido centradas no fazer artístico, ficando em segundo plano a leitura e a contextualização, dois aspectos fundamentais dos PCN's.

\section{Metodologia}


Cumpre, inicialmente, definir os termos. Transdisciplinaridade, nesta pesquisa, foi entendida no sentido de um processo no qual todos os professores de Arte estivessem articulados, planejando as aulas de cada um deles e, a seguir, avaliando e reformulando novos passos a seguir, conjuntamente.

Concepção do Método de Ensino - aplicaram-se princípios dos PCN's, acrecentando-se fundamentos semióticos, já que a semiótica discursiva possibilita a compreensão da produção artística como linguagem, possuindo todas, em comum, o plano de expressão (o que se percebe por meio de um ou mais dos cinco sentidos); e o plano de conteúdo (o que se compreende a partir do que se percebe). Assim, os fundamentos semióticos proporcionam uma visão integrada de todas as linguagens estéticas, propiciando aos alunos o trânsito entre elas, o que acabou sendo constatado em todas as etapas do TRANSARTE, embora apenas no TRANSARTE II tenha havido maio compreensão do fenômeno por parte dos professores.

Amostra - a amostra pesquisada, no TRANSARTE III, foi composta por uma turma de 16 alunos (as) do $5^{\circ}$ ano do Ensino Fundamental de uma escola particular de Florianópolis; eles possuem acesso a museus, cinema, teatro, entre outros bens e eventos culturais. A instituição é considerada publicamente como uma escola alternativa, inovadora e aberta a novas experiências educacionais, entre elas, a transdisciplinaridade.

Métodos de Pesquisa - foram utilizados como técnica de coleta de dados: a observação sistemática, testes (pré e pós-testes, redação dos alunos resultantes da observação de um vídeo animado). As observações foram fotografadas e anotadas em um caderno de campo. O uso de testes na pesquisa se deu conforme o entendimento de Lakatos e Marconi (1999), como testes de rendimento (ou de conhecimento). Os dados foram tratados qualitativa e quantitativamente. Na análise de conteúdo, o procedimento adotado foi a classificação segundo categorias relacionadas à construção de textos estéticos. Os parâmetros que geraram as categorias foram os vocábulos que designam conceitos estéticos, presentes nas diversas linguagens artísticas, decorrentes de estudos de Ramalho e Oliveira (1998; 2002).

Procedimentos - aconteceram diversas reuniões; na primeira, estavam presentes a direção, as coordenadoras pedagógicas, o professor de artes cênicas, a professora de música e as duas professoras de artes plásticas, bem como a coordenadora da pesquisa e 
as duas bolsistas de iniciação científica. A Equipe da Escola aderiu à pesquisa, demonstrando interesse. Foi escolhida uma turma do $5^{\circ}$ ano do Ensino Fundamental para aplicação da proposta, considerando-se que os professores das três linguagens (plástica, música e cênica) lecionavam nessa turma.

O projeto TRANSARTE previa um semestre para estudo da base teórica e planejamento das aulas, deixando a aplicação da proposta com os alunos para o semestre subseqüente; entretanto, a Direção propôs que se iniciasse a aplicação de imediato, pois o “caminho se faz ao caminhar". Foram agendadas reuniões quinzenais, com duração de uma hora.

As primeiras reuniões foram destinadas a apresentar e discutir a base teórica da proposta e integrá-la aos fundamentos e práticas educacionais adotados naquela Escola. As reuniões subseqüentes, que foram previstas para planejamento, avaliação e revisão permanente das aulas, integradamente, tomaram direções distintas das idealizadas no projeto da pesquisa, pois embora fossem realizadas e sugeridas leituras para a compreensão dos objetivos e preceitos do TRANSARTE, foi oportunizado pouco tempo para discussões e eventuais alterações na proposta original, de comum acordo, como era previsto.

As reuniões aconteceram com a presença da equipe pedagógica. Para a equipe de pesquisa, parecia um grande grupo, mas em alguns momentos estavam presentes mais pessoas que não iriam aplicar a proposta. As ausências dos professores que iriam aplicar a proposta, embora poucas e justificadas, prejudicaram o desenvolvimento do processo, pois se tratava de uma construção coletiva, e uma única falta de um dos professores de uma das linguagens comprometia o todo.

A proposta previa a escolha de uma imagem para ser utilizada como instrumento para a realização do pré e do pós-teste com os alunos. Tentando auxiliar a Equipe da Escola na escolha da imagem, um membro voluntário do grupo de pesquisa sugeriu que fosse usada uma animação, pelo fato desta abordar as linguagens plástica, cênica e musical. A sugestão foi aprovada pela Direção da Escola e partir daí a idéia "de fazer" o produto final (a animação) direcionou todo processo; ou seja, a criação da animação passou a ser o objetivo da equipe da Escola. 
Os professores adotaram a animação trazida pelas pesquisadoras e intitulada Peça por peça se constrói um amigo, produzida por Gabriela Dreher, criada por desenhos feitos manualmente e posteriormente editados, com a duração de 1 minuto, muda, apenas com trilha e efeitos sonoros. As professoras de plásticas realizaram o pré-teste, que consistiu na leitura, com descrição verbal, escrita e individual efetuada pelos alunos da animação descrita acima.

Iniciando a produção da animação, os professores dividiram a turma em três grupos. A distribuição das tarefas da construção da animação, entre os professores, deuse de forma segmentada. Nas aulas de plásticas, os alunos realizaram a confecção dos cenários e dos personagens (bonecos). O professor de teatro orientou a criação dos enredos, realizou os exercícios de interpretação e manipulação dos bonecos. A professora de música desenvolveu com os alunos as trilhas e efeitos sonoros das animações e a edição da animação se deu com a supervisão do professor de informática. Assim, as aulas seguiram o que havia sido estabelecido: a confecção de bonecos, cenários, trilha sonora e jogos teatrais.

Foi enfatizado, junto à Equipe da Escola, a importância das relações que se estabeleciam com a utilização dos elementos constitutivos das três linguagens durante o processo; mas os professores fixaram-se no produto final - animação - em detrimento dos conteúdos propostos. As relações entre as linguagens se resumiram a pinceladas realizadas pela professora de música - que relacionou elementos das linguagens musical aos da visual - e pelo professor de teatro - que na primeira aula trabalhou a ampliação do conceito de texto.

Terminado o processo de produção das animações, foi realizado o pós-teste, com a mesma imagem utilizada no pré-teste; ele foi entregue às pesquisadoras, após o que não houve mais possibilidade de encontros com os participantes da experiência, em função do final do ano, impossibilitando uma consistente avaliação de todo o processo.

\section{Resultados}

Foi verificada a freqüência de diferentes conceitos estéticos no discurso verbal escrito dos alunos, no pré e no pós-teste; ela foi quantificada e representada no gráfico abaixo: no eixo vertical se localiza uma régua contendo o número equivalente às citações 
de vocábulos e respectivos conceitos estéticos pertencentes a um repertório necessário para produção e leitura de imagens; no eixo vertical, cada número corresponde a um aluno.

No gráfico abaixo percebe-se a variação da citação de termos (e seus significados) relacionados às linguagens estéticas: quase todos os alunos ampliaram seu repertório, com duas exceções: o aluno 5 manteve a mesma frequiência de citação de repertório e o aluno 11 apresentou diminuição na freqüência.

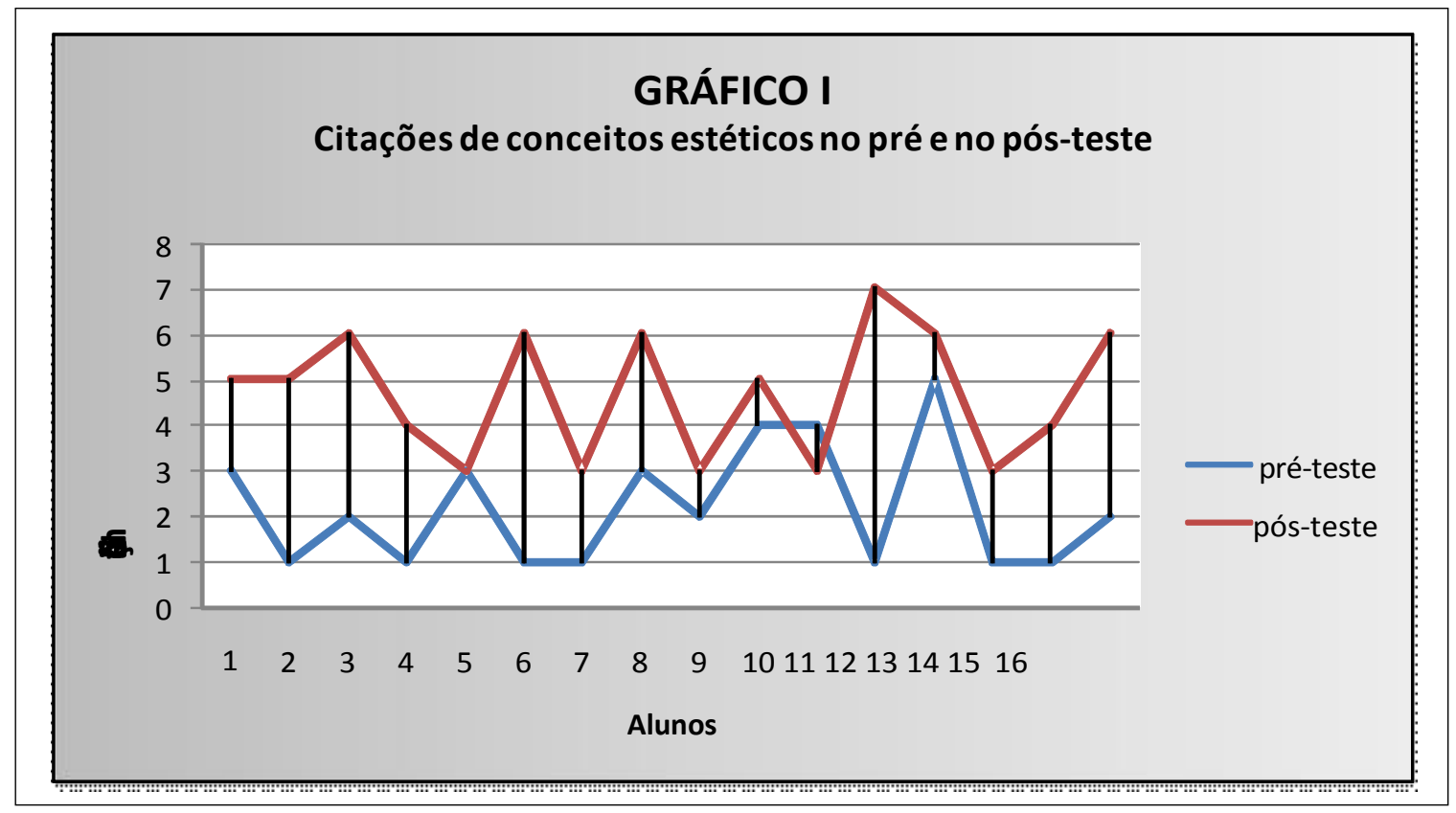

Além desses aspectos quantitativos, houve uma análise de conteúdo de pré e pós-testes. No pré-teste, a maioria das referências verbais foi ao enredo ou ao texto da animação; mas no pós-teste, nenhuma referência foi encontrada nas redações quanto a texto, sendo que ao enredo foram feitas apenas quatro referências. As observações se transferiram para a estruturação da linguagem.

Relacionando pré e pós-teste, considerando as três linguagens conjuntamente, dos dezesseis alunos pesquisados apenas três não deixaram transparecer em seu discurso uma compreensão mais ampla dos elementos constitutivos das três linguagens. Por outro lado, o entendimento dos elementos constitutivos se deu por meio do fazer, ou seja, a fala 
dos alunos demonstra que através do processo de criação da animação foram construídos conceitos mais aprofundados acerca dos vocábulos próprios da Arte, os quais, por sua vez, estavam diretamente relacionados com a linguagem da animação.

$\mathrm{Na}$ análise dos testes foi identificado o aumento de categorias referentes à linguagem cênica no pós-teste, demonstrando a preponderância da apreensão de conhecimentos referentes a esta linguagem, em relação às demais (música e artes visuais).

Foi ainda observado que doze alunos realizaram, no pós-teste, a leitura da animação Peça por peça se constrói um amigo por meio de comparações com a animação produzida por eles. Recorreram ao conhecimento recém construído pela prática naquele semestre para interpretar a animação objeto dos testes, relacionando analogias e destacando distinções entre a animação assistida e a animação produzida em aula.

Houve uma ampliação considerável dos fenômenos estéticos observados pelos alunos no pós-teste, comparando-se com o pré-teste aplicado preliminarmente: após a experiência objeto deste estudo, os alunos realizaram a leitura da animação com maior propriedade, conseguindo assim melhor apreensão dos elementos significantes e avançando no alcance do significado dos textos estéticos.

\section{Discussão}

$\mathrm{Na}$ análise do Gráfico I verifica-se que no pré-teste prevaleceram na redação dos alunos referências ao enredo e ao texto, que são considerações genéricas e próprias do senso comum; ao contrário, no pós-teste identificamos apenas quatro referências a enredo e nenhuma a texto; em compensação, os detalhes dos componentes da construção do texto e da significação ampliaram-se.

Este resultado já ocorreu nas outras etapas do TRANSARTE e mostra que no pré-teste, ou seja, antes da aplicação da proposta, os alunos, como o senso comum, observam apenas o discurso ou a narrativa de origem exclusivamente verbal, qual seja o enredo do filme, ou da animação, no caso.

Organizando os vocábulos citados nos testes, foram criadas categorias de análise e foi percebido que predominaram referências à linguagem cênica, que se alteraram, considerando pré e pós-teste; exemplificando-se: "tempo": 3 citações no pré e 1 no pós- 
teste; "fala": 3 tanto no pré quanto no pós-teste; "personagem": ampliação de 1 para 8 citações.

O desempenho evidente da apreensão de conhecimentos preponderantemente na linguagem cênica pode ser mostrado pelo acréscimo de categorias no pós-teste, portanto. São elas: "luz", "movimento" e "cenário", sendo que a categoria "luz" recebeu nove citações, de um total de dezesseis alunos; a categoria "movimento" recebeu doze citações; e a categoria "cenário" foi citada onze vezes.

Quanto ao repertório relacionado à linguagem musical, apenas duas categorias foram citadas no pré e também no pós-teste: "música" (percepção da existência de fundo musical na animação) e "efeitos sonoros". Entretanto, a freqüência se amplia, nos dois casos: "música" teve duas citações no pré-teste e quatro no pós-teste. Quanto a "efeitos sonoros", houve apenas uma ocorrência no pré-teste, mas cinco no pós-teste.

Com relação aos elementos da linguagem visual, no pré-teste os alunos perceberam apenas a categoria "cor". No pós-teste houve apenas o acréscimo de uma nova categoria: "proporção", citada por um aluno. Quanto à freqüência das citações da categoria "cor", quatro alunos referiram-se à cor no pré-teste, número que se manteve no pós-teste, embora os sujeitos que falavam de cor numa e outra situação fossem diferentes. A relevância do processo de criação na experiência vivida em aula foi constatada, no pósteste, pela compreensão do processo técnico de criação de ambas as animações por catorze alunos; onze alunos identificaram no pós-teste a linguagem plástica do desenho na animação Peça por peça se constrói um amigo; e sete alunos identificaram a linguagem cênica de formas animadas (bonecos) na animação criada por eles.

Houve também, por três alunos, o aprofundamento no significado dos textos estéticos, identificando a comunicação de idéias nas animações, bem como a importância do enredo (história), campo da intersemiose, como transparece em suas falas: "a história é a parte mais importante da animação, para ter animação é preciso ter uma história, muitas vezes ela precisa passar uma mensagem positiva"; "as duas animações tem um processo bem parecido (...) criar a história, fazer o roteiro".

Os alunos, de um modo geral, mostraram apreender os efeitos de sentido contidos nos elementos constitutivos “música”, "som”, "efeito sonoro”, “cenário” e 
"movimento", como demonstram suas falas, nas quais se evidenciam a presença das intersemioses: "percebemos que o cenário é importante para a história ter sentido"; “... muitas vezes é necessário efeitos sonoros para dar sentido à animação”; “... no movimento conseguimos sentir o que a animação quer nos 'passar' "; "quando a menina está pensativa há uma música de suspense e mistério".

Os dados obtidos pela observação permitem inferir que após a sugestão da animação pela equipe de pesquisa para realização do pré-teste, as reuniões passaram a ser para o planejamento e relato das atividades de produção da animação. Conforme as etapas foram avançando, as reuniões com o grupo de pesquisa foram se espaçando cada vez mais, parecendo que os professores entenderam que as tarefas referentes à produção das animações poderiam ser combinadas entre eles, dispensando a presença dos pesquisadores.

É relevante registrar que houve um distanciamento da proposta TRANSARTE, que previa os três momentos da Abordagem Triangular - fazer criativo, a leitura e a contextualização - tendo como suporte inicial a leitura de imagens. No caso em análise, o TRANSARTE III, o processo foi baseado no fazer.

Como em apenas poucos momentos os processos de ensino e aprendizagem abordaram a leitura e na contextualização, os alunos desenvolveram conhecimentos nas três linguagens da arte, direcionados especificamente para a linguagem da animação (linguagem sincrética), em virtude da vivência exclusiva do processo de criação ou fazer. Entretanto, foi verificado que, mesmo com o ensino centrado no fazer, é possível que os alunos estabeleçam inter-relações entre as linguagens.

\section{Conclusão}

No TRANSARTE III, a transdisciplinaridade não ocorreu no todo do processo, conforme previsto originalmente. O conceito de transdisciplinaridade foi construído a partir do escopo teórico-metodológico pedagógico, artístico e semiótico para processos de elaboração, leitura e contextualização no ensino das três linguagens (plástica, cênica e sonora). Os conhecimentos e práticas deveriam atravessar-se mutuamente, num trânsito que possibilitasse a percepção de analogias e distinções. Portanto, como praticamente não aconteceram duas das dimensões da Abordagem 
Triangular - leitura e contextualização - o processo transdisciplinar não aconteceu como proposto. Se houve alguma dimensão transdisciplinar, restringiu-se exclusivamente ao âmbito do fazer.

As intersemioses, embora tenham se dado de forma aleatória tendo por base o fazer, foram estabelecidas, atestando que os alunos conseguem perceber paralela ou simultaneamente - ou seja, em relação - os fenômenos estéticos que se estruturam nas linguagens distintas (visual, cênica, audiovisual, sonora). Por conseguinte, a aplicação da proposta demonstrou que ela possibilita e auxilia na leitura de imagens sincréticas.

A opção por uma animação (como produto) não era a melhor, para o pré e o pósteste e, conseqüentemente, para a própria proposta, pois a animação é híbrida, um todo único, sendo, portanto, uma outra linguagem. Isto dificulta o estabelecimento e a percepção, por parte do aluno, de interações (intersemioses). Entretanto, a sugestão partiu, equivocadamente, de um membro voluntário da equipe de pesquisa; e foi adotada por todos na Escola com entusiasmo, impedindo a própria coordenação da pesquisa de argumentar eficazmente e retomar a proposta dentro dos preceitos originais.

Por que essa Escola, assim como a maioria das outras, ainda privilegia o "produto"? Afirmar que seria a fim de demonstrar aos pais dos alunos as atividades e produtos concretos por eles realizados, seria prematuro e pode servir como sugestão para outras pesquisas.

Entre as dificuldades encontradas, destacamos o pouco tempo que foi disponibilizado para a aplicação da proposta na Escola, apenas um semestre, concorrendo ainda com outros afazeres dos professores, compromissos da instituição e feriados. Disto decorreu a não compreensão, pela Equipe da Escola, da proposta em si; conseqüentemente, não houve construção coletiva transdisciplinar, apenas divisões de tarefas que caracteriza a interdisciplinaridade e não a transdisciplinaridade. O processo foi também prejudicado pela falta de avaliação final conjunta entre Escola e grupo de pesquisa.

$\mathrm{O}$ aumento de categorias no pós-teste em relação ao pré-teste mostra a ampliação do repertório estético dos alunos, já que, no pré-teste prevaleceram referências ao enredo e ao texto, ou seja, narrativas genéricas, apenas; ao contrário, no pós-teste foram feitas apenas quatro referências ao enredo e nenhuma a texto, ocorrendo aumento 
no número de citações de conceitos estéticos e avanço na apreensão da significação da imagem. Portanto, concluímos que, no TRANSARTE III, houve transdisciplinaridade apenas no fazer artístico; mas houve intersemioses na percepção dos alunos, além de ampliação da percepção dos elementos constitutivos das diversas linguagens, pressuposto para a percepção de intersemioses, e o avanço na percepção e na leitura de imagens.

Os resultados obtidos demonstram que a proposta TRANSARTE pode ser mais explorada nos processos de ensino e aprendizagem da Arte, possibilitando aos alunos uma apreensão mais acurada dos fenômenos estéticos, imagemização (alfabetização visual) e o conseqüente acesso à cidadania, que só se dá a partir da compreensão dos significados que gravitam em torno de nós, no mundo social, pois só imagemizados poderemos, enfim, fazer nossas escolhas, com liberdade.

\section{Referências Bibliográficas:}

ARNHEIM, R. Arte e Percepção Visual: uma psicologia da visão criadora. Trad. de Yvonne Terezinha de Faria. São Paulo: Pioneira/ USP, 1986.

BARBOSA, Ana Mae. Arte-Educação: Conflitos/Acertos. São Paulo: Max Limonad, 1984.

. Tópicos Utópicos. Belo Horizonte: C/Arte, 1998.

GREIMAS, A. J. \& J. COURTÉS. "Semiótica Figurativa e Semiótica Plástica". Trad. de Ignácio Assis da Silva. Revista Brasileira de Semiótica. São Paulo: ABS, n. 4, jun. de 1984.

KANDISNKY, W. Ponto, Linha, Plano. Lisboa: Edições 70, 1996.

LAKATOS, Eva Maria; MARCONI, Marina de Andrade. Técnicas de Pesquisa: planejamento e execução de pesquisas, elaboração, análise e interpretação de dados. 4 ed. São Paulo: Atlas, 1999.

MELO, M. F.; BARROS, V. M.; SOMMERMAN, A. "Transdisciplinaridade e Conhecimento". In: Educação e Transdisciplinaridade II. São Paulo: Triom, 2002.

NICOLESCU, B. "Contracapa". In: Educação e Transdisciplinaridade II. São Paulo: TRIOM, 2002.

PAVIS, P. Diccionnaire du Théâtre. Paris: Éditions Sociales, 1990. 
PIGNATARI, D. O que é Comunicação Poética. São Paulo: Brasiliense, 1989.

OLIVEIRA, Ana Claudia. Semiótica Plástica. São Paulo: Hacker, 2005.

OSTROWER, Fayga. Universos da Arte. Rio de Janeiro: Campus, 1986.

RAMALHO E OLIVEIRA, S. Imagem também se lê. São Paulo, Rosari, 2005.

Arte, estética do cotidiano e relações culturais. Lille,

Pesquisa de Pós-doutorado, 2002.

SANTAELLA, L. O que é Semiótica. São Paulo: Brasiliense, 1983.

SCHAFER, M. O Ouvido Pensante. São Paulo: UNESP, 1991.

ZABALA, A. "Os enfoques didáticos". In: O Construtivismo em Sala de Aula. $6^{\text {a }}$. ed. São Paulo: Ática, 2004.

\begin{abstract}
This article describes the third phase of the TRANSARTE Project, witch is a proposal for Art teaching besed on Semiotics. The first experiments in this project were carried out at a federal school, the second phase took place at state and city schools and the third stage described here was carried out at a private school. A range of problems with the teachers meant that the original objective of transdisciplinarity had to be reduced to interdisciplinarity. Nevertheless, the results obtained with these students reveal relevant data with relation to the perception of intersemiosis, to increasing the repertoire of concepts and to analysis of images, if one considers performance before and after the tests.
\end{abstract}

KEY WORDS: art education; transdisciplinarity; intersemiosis. 